\title{
Demands for carbohydrates as major energy substrates depend on the preimplantation developmental stage in pig embryos: Differential use of fructose by parthenogenetic diploids before and after the 4-cell stage in the pig
}

\author{
Mihiro SHIBUTANI'), Jibak LEE'), Takashi MIYANO'1) and Masashi MIYAKE2) \\ 1) Graduate School of Agricultural Science, Kobe University, Kobe 657-8501, Japan \\ 2) Integrated Research Center of Kobe University, Kobe 650-0047, Japan
}

\begin{abstract}
The embryo culture technique has been improving, but the detailed demands for energy substrates such as glucose, fructose, pyruvate and lactate of preimplantation embryos are still unclear. In the present study, the demands of pig preimplantation embryos at each different developmental stage were investigated by use of parthenogenetic diploids as a model of pig preimplantation embryos. Pig parthenogenetic diploids showed different use of glucose and fructose before and after the 4-cell stage. Although glucose supported the development of pig embryos throughout the preimplantation stages and even maintained the expansion and hatching of blastocysts, it suppressed development to the blastocyst stage when glucose coexisted with pyruvate and lactate from $4 \mathrm{~h}$ after activation, but not after $48 \mathrm{~h}$ (early 4-cell stage). Since ketohexokinase that metabolizes fructose was not expressed in 2-cell and 4-cell diploids, a medium that included only fructose as a major energy substrate did not support early cleavage of pig diploids beyond the 4-cell stage, and almost no diploids developed to the morula stage just as in a medium without carbohydrates. These results may explain the different suppressive effects on pig preimplantation development between glucose and fructose when pyruvate and lactate were present in a medium. In addition, 4-cell diploids that had been cultured in a medium with pyruvate and lactate developed to the expanded blastocyst stage without any carbohydrates as a major energy substrate. These results show that the demands for carbohydrates are different depending on the developmental stage in pig preimplantation embryos.
\end{abstract}

Key words: Fructose, Parthenogenetic diploids, Pig, Preimplantation development

(J. Reprod. Dev. 61: 106-115, 2015)

A n effective mammalian embryo culture system contributes to development of not only biology but also medical biotechnologies or agricultural science. Energy substrates in a medium have been studied for a long time to improve the culture system, but there still remain many unresolved problems, for example, the effects of combination of substrates in a medium, the different demands for substrates between species or developmental stages and so on. Since glucose supports blastocyst formation, it is one of the main energy substrates for the preimplantation development of mammalian embryos. But it has been also reported that glucose inhibits embryo development in hamsters [1] and cattle [2]. In the case of mice, it has been shown that the presence of glucose in a medium inhibits early embryonic cleavage [3].

There are two kinds of opinion regarding whether a medium for pig embryo culture should include glucose or not. Pig preimplantation embryos have been generally cultured in media including glucose,

Received: July 24, 2014

Accepted: November 29, 2014

Published online in J-STAGE: January 8, 2015

(C2015 by the Society for Reproduction and Development

Correspondence: M Miyake (e-mail: miyake@kobe-u.ac.jp)

This is an open-access article distributed under the terms of the Creative Commons Attribution Non-Commercial No Derivatives (by-nc-nd) License $<\mathrm{http}: / /$ creativecommons.org/licenses/by-nc-nd/3.0/>. such as modified Whitten's medium (mWM) [4-6] and North Carolina State University medium 23 (NCSU 23) [7]. These media include glucose with or without pyruvate and lactate and support embryonic development to the blastocyst stage in the pig. It has been reported that pig embryos metabolize glucose throughout preimplantation development and that the utilization of glucose is much higher in embryos after compaction than in those before the 8-cell stage [8]. It has also been reported that replacement of glucose with pyruvate and lactate in NCSU-37 until $58 \mathrm{~h}$ after the beginning of in vitro culture improved development of pig embryos to the blastocyst stage, while embryos cultured in NCSU-37 including $5.56 \mathrm{mM}$ glucose showed lower embryonic development at the early preimplantation stages [9]. These studies suggested that pig embryos at early cleavage stages might prefer carbohydrates rather than glucose as energy substrates. Others have reported that glucose enhances the viability of pig embryos at the post-compaction and blastocyst stages [10]. These results suggest that physiological characteristics relating to glucose utility are different between early cleavage stages and during blastocyst formation in the preimplantation development of pig embryos. Yoshioka et al. [11] showed that pyruvate and lactate without glucose provided the best results for blastocyst formation in pig in vivo fertilized embryos.

It has been shown that fructose can substitute for glucose during preimplantation embryo development [12] and that fructose can 
increase the cell number of a blastocyst in cattle [13]. Furthermore, exposure of embryos in the preimplantation period to fructose increased the rate of embryos that implanted after transfer to recipients and the number of cells in hamster blastocysts [1]. Supplementation of a culture medium with fructose instead of glucose on day 3 improved the rate of blastocyst formation, and it increased the number of cells and decreased the ratio of apoptotic cells in pig blastocysts [14]. On the other hand, addition of fructose alone from the beginning of culture of in vitro fertilized pig embryos causes a very low cleavage rate and no blastocyst formation [15]. Therefore, the addition of fructose does not always supports pig embryonic development. These studies suggest that characteristics of fructose metabolism are also different between early cleavage stages and post-compaction stages in pig preimplantation development. Although it is suggested that fructose is rather better than glucose for in vitro blastocyst formation in many mammalian species $[1,12,13]$ including pigs [14], the details of fructose utility by preimplantation embryos are still unclear.

Although there are some discrepancies among the results in the pig experiments described above, the difference in glucose or fructose utility is generally explained by zygotic gene activation (ZGA). ZGA is believed to occur around the late 4-cell stage [16], and glucose improves the conditions of embryos around and/or after compaction in pigs [10]. Fructose may be metabolized by pig embryos after ZGA. These results suggest that some glycolytic enzymes become active at a certain level after ZGA in pig preimplantation embryos.

In the present study, electrically activated diploids were used instead of in vitro fertilized embryos because of their high developmental ability to the blastocyst stage [17] and high incidence of polyspermic fertilization in the case of in vitro fertilization in pigs. To examine the utility of a carbohydrate(s), glucose, fructose, pyruvate and lactate, and a combination of glucose or fructose with pyruvate and lactate during pig preimplantation embryonic development, parthenogenetically activated diploids were cultured in a chemically defined medium with different carbohydrates, and the characteristics of preimplantation development were examined. Furthermore, we expected that the mRNA expressions of glycolytic enzymes in diploids would be different in each developmental stage, because the expression pattern indicated hexose demands in diploids. Therefore, the expression of hexokinase II (HKII), ketohexokinase (KHK) and glucokinase $(G C K)$ mRNAs, which mediate the first step of glucose and/or fructose metabolism, were also examined to assist in understanding the results of preimplantation development of pig parthenogenetic diploids in media including glucose and fructose.

\section{Materials and Methods}

\section{Collection, in vitro maturation and activation of oocytes}

Pig ovaries were collected at local slaughterhouses and transported to our laboratory within $2 \mathrm{~h}$. Ovaries were washed once with $0.2 \%$ $(\mathrm{w} / \mathrm{v})$ cetyltrimethylammonium bromide (CETAB; Wako Pure Chemical Industries, Osaka, Japan) and twice with $\mathrm{Ca}^{2+}$ - and $\mathrm{Mg}^{2+}$ free Dulbecco's phosphate buffered saline (PBS) including $0.1 \%$ (w/v) polyvinyl alcohol (PVA; Sigma-Aldrich Chemical, St. Louis, MO, USA). Follicles that were 4-6 $\mathrm{mm}$ in diameter were cut out in PBS-PVA from ovaries using a pair of disposable surgical scalpels. Cumulus-oocyte-granulosa cell complexes (COGCs) were collected from follicles in tissue culture medium 199 (TCM-199) buffered with $25 \mathrm{mM}$ 2-[4-(2-Hydroxyethyl)-1-piperazinyl]ethanesulfonic acid (HEPES; Dojindo Molecular Technologies, Kumamoto, Japan) (HEPES-199), and then washed with HEPES-199 followed by washing twice with the maturation-culture medium without human menopausal gonadotropin (hMG; ASKA Pharmaceutical, Tokyo, Japan). Several follicular shells were collected from healthy follicles that were 4-6 $\mathrm{mm}$ in diameter and then freed from the lining granulosa cells. Thirty to ninety COGCs were maturation cultured with a few follicular shells for 44-48 h in a $2.0 \mathrm{ml}$ maturation-culture medium, which was bicarbonate-buffered TCM-199 including 10\% (v/v) heat-treated fetal calf serum (FCS; Biocell Laboratories, Carson, CA, USA), $0.1 \mathrm{mg} / \mathrm{ml}$ sodium pyruvate, $0.08 \mathrm{mg} / \mathrm{ml}$ kanamycin sulfate, $2.2 \mathrm{mg} / \mathrm{ml}$ sodium bicarbonate and $0.1 \mathrm{IU} / \mathrm{ml} \mathrm{hMG}$, in a $\mathrm{CO}_{2}$ incubator under a humidified atmosphere with $5 \% \mathrm{CO}_{2}$ and $95 \%$ air at $38.5 \mathrm{C}$. After maturation culture, $200 \mu \mathrm{l}$ PBS-PVA including $0.1 \%(\mathrm{w} / \mathrm{v})$ hyaluronidase was added to each $2.0 \mathrm{ml}$ maturation-culture medium. Then, oocytes were freed from cumulus cells in PZM3 [11] by mechanical pipetting and then washed three times in a field solution that consisted of $0.30 \mathrm{mM}$ mannitol, $0.05 \mathrm{mM} \mathrm{CaCl}_{2}, 0.10 \mathrm{mM} \mathrm{MgSO}_{4}$ and $0.01 \%$ (w/v) PVA. Washed oocytes were transferred into $100 \mu \mathrm{l}$ of the field solution, which was added between parallel stainless electrodes in a chamber (FTC-03; Shimadzu, Kyoto, Japan) and activated by a single square wave electrostimulation at $1,500 \mathrm{~V} / \mathrm{cm}$ DC for $100 \mu \mathrm{sec}$. Oocytes subjected to electrostimulation were cultured in PZM3 including 5 $\mu \mathrm{g} / \mathrm{ml}$ cytochalasin B (Sigma-Aldrich) for $4 \mathrm{~h}$ to inhibit ejection of the second polar body to produce presumptive diploids.

\section{Preparation of culture media for preimplantation development}

In this study, 6 different media for preimplantation development, which were based on PZM3 or PZM3 without pyruvate and lactate (PZM), were used. PZM3 and PZM including $5.56 \mathrm{mM}$ glucose or fructose were prepared, and the media were named $P Z M 3+G$, $\mathrm{PZM} 3+\mathrm{F}, \mathrm{PZM}+\mathrm{G}$ and $\mathrm{PZM}+\mathrm{F}$, respectively. $\mathrm{PZM}$ was supplemented with $2.0 \mathrm{mM} \mathrm{CaCl}_{2}$ to supplement for the deficiency of $\mathrm{Ca}^{2+}$ caused by the removal of calcium lactate from PZM3, and the osmotic pressure in each medium was kept constant by adjusting the $\mathrm{NaCl}$ concentration level (Table 1).

\section{Embryo culture}

Diploids treated with cytochalasin B were washed three times in PZM3 and then 2 times in each culture medium. Groups of 8-12 presumptive diploids were cultured in a $10 \mu 1$ droplet of each medium under mineral oil (Wako) for $216 \mathrm{~h}$ in a $\mathrm{CO}_{2}$ incubator under a humidified atmosphere with $5 \% \mathrm{CO}_{2}$ and $95 \%$ air at $38.5 \mathrm{C}$. Cultured diploids were observed, and their developmental stages were morphologically determined every $24 \mathrm{~h}$. In all experiments, the culture media were preincubated more than $2 \mathrm{~h}$ before use for equilibration of the gas phase and temperature. As it was preliminarily confirmed that there was no difference in the preimplantation development between diploids that were cultured with replacement of media every 3-days and those without replacement of media, experiments were performed without additional replacement of culture media except for the times described in the experimental design. 
Table 1. Components of each medium used in this study

\begin{tabular}{|c|c|c|c|c|c|c|c|}
\hline \multicolumn{2}{|l|}{ Components } & \multirow{2}{*}{$\frac{\text { PZM3 }^{\text {a) }}}{108.00}$} & \multirow{2}{*}{$\frac{\mathrm{PZM} 3+\mathrm{G}}{105.22}$} & \multirow{2}{*}{$\frac{\mathrm{PZM} 3+\mathrm{F}}{105.22}$} & \multirow{2}{*}{$\frac{\mathrm{PZM}+\mathrm{G}}{105.42}$} & \multirow{2}{*}{$\frac{\mathrm{PZM}+\mathrm{F}}{105.42}$} & \multirow{2}{*}{$\begin{array}{r}\text { PZM } \\
108.20\end{array}$} \\
\hline $\mathrm{NaCl}$ & $\mathrm{mM}$ & & & & & & \\
\hline $\mathrm{KCl}$ & $\mathrm{mM}$ & 10.00 & 10.00 & 10.00 & 10.00 & 10.00 & 10.00 \\
\hline $\mathrm{KH}_{2} \mathrm{PO}_{4}$ & $\mathrm{mM}$ & 0.35 & 0.35 & 0.35 & 0.35 & 0.35 & 0.35 \\
\hline $\mathrm{MgSO}_{4} \cdot 7 \mathrm{H}_{2} \mathrm{O}$ & $\mathrm{mM}$ & 0.40 & 0.40 & 0.40 & 0.40 & 0.40 & 0.40 \\
\hline $\mathrm{NaHCO}_{3}$ & $\mathrm{mM}$ & 25.07 & 25.07 & 25.07 & 25.07 & 25.07 & 25.07 \\
\hline Na-pyruvate & $\mathrm{mM}$ & 0.20 & 0.20 & 0.20 & - & - & - \\
\hline Ca-lactate $\cdot 5 \mathrm{H}_{2} \mathrm{O}$ & $\mathrm{mM}$ & 2.00 & 2.00 & 2.00 & - & - & - \\
\hline Glucose & $\mathrm{mM}$ & - & 5.56 & - & 5.56 & - & - \\
\hline Fructose & $\mathrm{mM}$ & - & - & 5.56 & - & 5.56 & - \\
\hline $\mathrm{CaCl}_{2}$ & $\mathrm{mM}$ & - & - & - & 2.00 & 2.00 & 2.00 \\
\hline L-glutamine & $\mathrm{mM}$ & 1.00 & 1.00 & 1.00 & 1.00 & 1.00 & 1.00 \\
\hline Hypotaurine & $\mathrm{mM}$ & 5.00 & 5.00 & 5.00 & 5.00 & 5.00 & 5.00 \\
\hline $\mathrm{EAA}^{\mathrm{b})}$ & $\mathrm{ml} / 1$ & 20.00 & 20.00 & 20.00 & 20.00 & 20.00 & 20.00 \\
\hline NEAA $^{c)}$ & $\mathrm{ml} / 1$ & 10.00 & 10.00 & 10.00 & 10.00 & 10.00 & 10.00 \\
\hline Kanamycin & $\mathrm{mg} / \mathrm{ml}$ & 0.08 & 0.08 & 0.08 & 0.08 & 0.08 & 0.08 \\
\hline BSA & $\mathrm{mg} / \mathrm{ml}$ & 3.00 & 3.00 & 3.00 & 3.00 & 3.00 & 3.00 \\
\hline Osmolality & $\mathrm{mOs}$ & 300.04 & 300.04 & 300.04 & 300.04 & 300.04 & 300.04 \\
\hline
\end{tabular}

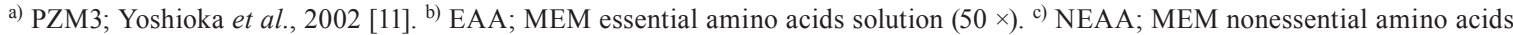
solution $(100 \times)$.

Detection of apoptotic cells by the terminal deoxynucleotidyl transferase dUTP nick end labeling (TUNEL) method

Apoptotic cells were detected with the DeadEnd ${ }^{\mathrm{TM}}$ Fluorometric TUNEL System (Promega, Madison, WI, USA) in blastocysts. Briefly, blastocysts were collected at $144 \mathrm{~h}$ after electrostimulation and fixed with PBS-PVA including 4\% (w/v) paraformaldehyde and $0.2 \%$ $(\mathrm{v} / \mathrm{v})$ Triton $\mathrm{X}$ for $25 \mathrm{~min}$ at room temperature. Fixed blastocysts were washed 3 times in PBS-PVA and sunk into $50 \mu 1$ equilibration buffer for $10 \mathrm{~min}$ at room temperature. Then, blastocysts were placed into $50 \mu 1$ reaction cocktail, which consisted of $45 \mu 1$ equilibration buffer, $5 \mu 1$ nucleotide mix and $1 \mu \mathrm{rTdT}$ enzyme. The TUNEL reaction was carried out at $37.0 \mathrm{C}$ in the dark for $1 \mathrm{~h}$ and stopped by addition of $50 \mu 1$ of $2 \times \mathrm{SSC}$ to the reaction cocktail. Blastocysts were washed 3 times in PBS-PVA. All nuclei were counterstained by Hoechst 33342. The total number of cells and the number of TUNEL-positive cells in each blastocyst were counted.

\section{Detection of mRNA expression of hexokinase II (HKII),} glucokinase (GCK) and ketohexokinase (KHK)

Forty-eight to fifty embryos that developed to the most dominant stages in each culture period were pooled for each $24 \mathrm{~h}$ culture period. Total RNA was extracted from embryos of each group using a GenElute ${ }^{\mathrm{TM}}$ Mammalian Total RNA Miniprep Kit (Sigma-Aldrich) according to the manufacturer's instructions. Then, RNA was isolated and reverse transcribed into cDNA using SuperScript II Reverse Transcriptase (Invitrogen, Carlsbad, CA, USA) in a total volume of $20 \mu 1$. The first reaction mixture consisted of $1 \mu 1$ of oligo (dT), 8 $\mu 1$ of RNA and $1 \mu 1$ of $10 \mathrm{mM}$ dNTP mix. This reaction was carried out for $5 \mathrm{~min}$ at $65 \mathrm{C}$, and then $2 \mu \mathrm{l}$ of $10 \times \mathrm{RT}$ buffer, $4 \mu \mathrm{l}$ of 25 $\mathrm{mM} \mathrm{MgCl} 2,2 \mu 1$ of $0.1 \mathrm{M}$ DTT, $0.25 \mu 1$ SuperScript II RT (reverse transcriptase) with $0.75 \mu 1$ water and $1 \mu 1$ RNase OUT recombinant RNase inhibitor was added to each tube. The reverse transcription
(RT) reaction was carried out at $42 \mathrm{C}$ for $50 \mathrm{~min}$, followed by an inactivation step at $70 \mathrm{C}$ for $15 \mathrm{~min}$. The concentration of each synthesized cDNA was measured and diluted by $400 \mu \mathrm{g} / \mathrm{ml}$. All RT products of the cDNAs were stored at $-20 \mathrm{C}$ until use.

Expressions of $H K I I, G C K$ and $K H K$ were analyzed by RT-PCR to determine whether parthenogenetic diploids had potency for glucose metabolism during preimplantation development. PCR was run in a C1000 Thermal Cycler (Bio-Rad Laboratories, Hercules, CA, USA) using a program consisting of a first step at $94 \mathrm{C}$ for 2 min followed by 45 repetitions of denaturation at $94 \mathrm{C}$, annealing at $56 \mathrm{C}$ and extension at $72 \mathrm{C}$ each for $30 \mathrm{sec}$, and any remaining single-strand DNA was fully extended at $72 \mathrm{C}$ for $3 \mathrm{~min}$. All primer pairs were designed to detect exon domains. The sequences of the primers are listed in Table 2. Pig poly-ubiquitin mRNA $(U B C)$ was used as a positive control for the reaction [18].

\section{Experimental design}

Experiment 1: Effects of addition of glucose or fructose to a chemically defined medium including pyruvate and lactate (PZM3) on preimplantation development (see Fig. 1A).

All activated oocytes were cultured in PZM3 with cytochalasin $\mathrm{B}$ to suppress extrusion of the second polar body until $4 \mathrm{~h}$ after electrostimulation. Then replacement of media with glucose or fructose was performed at $4 \mathrm{~h}$ (just after the cytochalasin B treatment), 48 $\mathrm{h}$ and $72 \mathrm{~h}$ after electrostimulation to examine the stage-specific effects of these carbohydrates on preimplantation development. When media were exchanged at $4 \mathrm{~h}$ after electrostimulation, diploids were directly cultured in PZM3, PZM3 + G and PZM3 $+F$. When media were exchanged at $48 \mathrm{~h}$ and $72 \mathrm{~h}$, diploids were cultured in PZM3 until 48 or $72 \mathrm{~h}$, and then they were cultured in PZM3, PZM3 $+\mathrm{G}$ and PZM3+F. According to Kure-Bayashi et al. [19], diploids that were degenerated or showed developmental delay more than $48 \mathrm{~h}$ behind 
Table 2. Primer sequences used in Experiment 3

\begin{tabular}{cllc}
\hline \multicolumn{2}{c}{ Genes } & \multicolumn{1}{c}{ Sequence } & GenBank accession number \\
\hline \multirow{2}{*}{ HKII } & Forward & TGAAACCAAGTTCCTGTCTCA & DQ432056.1 \\
& Reverse & TTGGCAAAGTGAGGATGTAGC & \\
GCK & Forward & TTTGTTGCATGTCTGCACTG & XM_003484067.1 \\
& Reverse & TAGGTGATCAGCAGCTTCCC & \\
KHK & Forward & TACGGGGATGTGGTGTTTGT & XM_003125302.2 \\
& Reverse & ATGCTCTTCCCCTGGGAGA & \\
\multirow{2}{*}{ BBC } & Forward & TTCGTGAAGACCTTGACTG & M18159 \\
& Reverse & GGACTCCTTCTGGATGTTG & \\
\hline
\end{tabular}

Pig ubiquitin mRNA $(U B C)$ was used as a positive control [18].

(A) Experiment 1

\begin{tabular}{|c|c|c|c|}
\hline \multirow{3}{*}{$C B$} & \multicolumn{2}{|r|}{$P Z M 3, P Z M 3+G$ or $P Z M 3+F$} & Fig. 3 \\
\hline & $P Z M B$ & $\mathrm{PZM} 3, \mathrm{PZM} 3+\mathrm{G}$ or $\mathrm{PZM} 3+\mathrm{F}$ & Fig. 4 \\
\hline & $\mathrm{PZM} 3$ & $\mathrm{PZM} 3, \mathrm{PZM}+\mathrm{G}$ or $\mathrm{PZM} 3+\mathrm{F}$ & Fig. 5 \\
\hline $\begin{array}{l}04 \\
\uparrow \\
\text { elect }\end{array}$ & 48 & 72 & \\
\hline
\end{tabular}

(B) Experiment 2

\begin{tabular}{|c|c|c|c|}
\hline \multirow{2}{*}{$C B$} & \multicolumn{2}{|c|}{$P Z M 3, P Z M 3+G, P Z M+G, P Z M+F$ or $P Z M$} & Fig. 6 \\
\hline & PZM3 & $\mathrm{PZM} 3, \mathrm{PZM}+\mathrm{G}, \mathrm{PZM}+\mathrm{F}$ or $\mathrm{PZM}$ & Fig. 7 \\
\hline & & & (h) \\
\hline
\end{tabular}

Fig. 1. Diagrams of methods for embryo culture. All oocytes were cultured in PZM3 including cytochalasin B (CB) for $4 \mathrm{~h}$ after electrostimulation to suppress ejection of the second polar body. See the experimental design section in the Materials and Methods.

the most dominant stages at each observation time were classified to abnormal. Therefore, only normally developed embryos were selected for subsequent culture when medium was replaced at $48 \mathrm{~h}$ and $72 \mathrm{~h}$, respectively. In all cases, diploids were cultured until 216 $\mathrm{h}$ after electrostimulation and the stages of embryonic development were observed and recorded every $24 \mathrm{~h}$.

Experiment 2: Effects of addition of glucose or fructose to a chemically defined medium without pyruvate and lactate (PZM) on preimplantation development (see Fig. 1B).

As hexoses were added to PZM3 including pyruvate and lactate in Experiment 1, the net effects of glucose and fructose on the preimplantation development of pig parthenogenetic diploids were examined in Experiment 2. Activated diploids were cultured in PZM3 (positive control), $\mathrm{PZM} 3+\mathrm{G}, \mathrm{PZM}+\mathrm{G}, \mathrm{PZM}+\mathrm{F}$ and $\mathrm{PZM}$ (negative control). Diploids were cultured in a medium with glucose or fructose added at 4 and $72 \mathrm{~h}$ after electrostimulation. Since the 4-cell stage period is almost twice that of the 2-cell period in pig preimplantation development [19], only 4-cell diploids were selected for subsequent culture when the medium was replaced at $72 \mathrm{~h}$. In both cases, diploids were cultured until $216 \mathrm{~h}$ after electrostimulation, and the stages of embryonic development were observed and recorded every $24 \mathrm{~h}$. A sample of blastocysts cultured in each medium were collected at $144 \mathrm{~h}$ after electrostimulation and subjected to the TUNEL reaction.
The number of apoptotic cells and the total number of cells were counted, and the ratio of apoptotic cell numbers to total cell numbers in each blastocyst (apoptotic index) was calculated.

Experiment 3: Detection of mRNA of hexokinase II (HKII), glucokinase $(G C K)$ and ketohexokinase $(K H K)$ in embryos during preimplantation development.

The results of Experiment 2 suggest that pig preimplantation embryos showed a different ability to use fructose from that of glucose. Therefore, the mRNA expressions of $H K I I$ and GCK, which catalyzed the first step of glucose metabolism, and $K H K$, which catalyzed the first step of fructose metabolism, were examined by RT-PCR in the parthenogenetic diploids at each preimplantation developmental stage.

\section{Statistical analysis}

Values for rates of embryonic development and apoptotic ratios were subjected to arcsine transformation in each replication, and then transformed values were analyzed using one-way ANOVA. If the ANOVA was a significant and positive, the Tukey-Kramer method was used to compare the experimental groups. Total cell numbers in blastocysts were logarithmically transformed and then analyzed using one-way ANOVA followed by the Tukey-Kramer method.

\section{Results}

Experiment 1: Effects of glucose or fructose addition to a chemically defined medium including pyruvate and lactate (PZM3) on preimplantation development

A typical result of embryonic development when diploids were cultured in PZM3 to $144 \mathrm{~h}$ after electrostimulation is shown in Fig. 2. The results of Experiment 1 are summarized in Figs. 3, 4 and 5.

When diploids were cultured in PZM3 with glucose or fructose from $4 \mathrm{~h}$ after electrostimulation, the proportions of cleaving diploids showed no significant difference between diploids cultured in PZM3, PZM3+G and PZM3+F at the 2-cell (24 h), early 4-cell (48 h) and late 4-cell stages ( $72 \mathrm{~h}$ after electrostimulation) (Fig. 3). The proportions of normally developed diploids were also not significantly different among the culture media until $120 \mathrm{~h}$. On the other hand, the proportions of morula formation at $96 \mathrm{~h}$ and blastocyst formation later than $120 \mathrm{~h}$, except for at $216 \mathrm{~h}$, were significantly higher in PZM3 and in PZM3+F than in PZM3 $+\mathrm{G}(\mathrm{P}<0.05)$, because the proportion of normally developed diploids meant that of blastocyst 


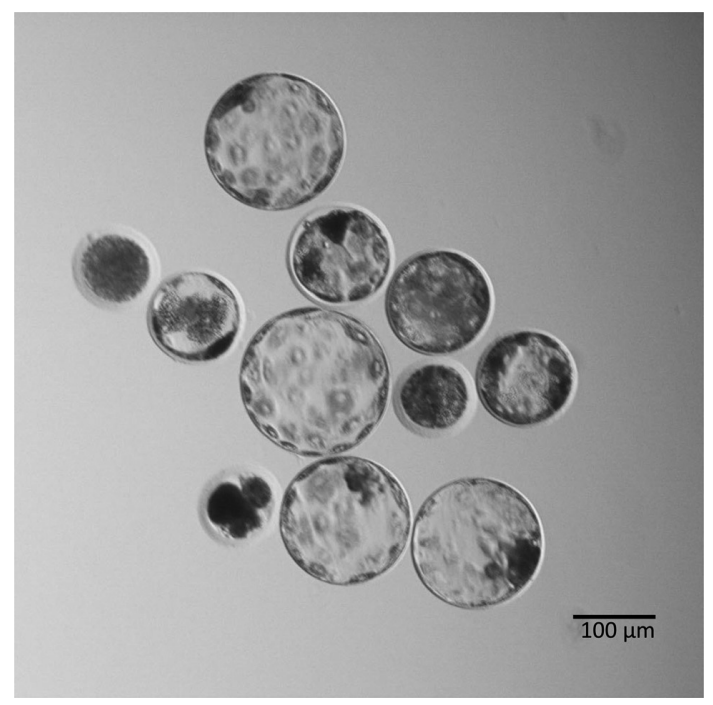

Fig. 2. Typical diploids at the blastocyst stage that were cultured in PZM3 until 144 h. Eight out of $11(73 \%)$ cultured diploids developed to the blastocyst or expanded blastocyst stage.

formation later than $168 \mathrm{~h}$.

When diploids were cultured in PZM3 $+\mathrm{G}$ or PZM3 $+\mathrm{F}$ from $48 \mathrm{~h}$ after electrostimulation, there were no significant differences in the proportions of normally developed diploids among PZM3, PZM3 $+\mathrm{G}$ and PZM3 $+\mathrm{F}$ at any observation point (Fig. 4). When fructose and glucose were supplemented at $72 \mathrm{~h}$ after electrostimulation (Fig. 5 ), the proportion of total blastocysts (actually expanded, hatching and hatched blastocysts) at $144 \mathrm{~h}$ tended to be higher in PZM3+F compared with those in the other media $(\mathrm{P}>0.05)$. The proportion of hatching/hatched blastocysts at $216 \mathrm{~h}$ in PZM3 $+\mathrm{F}$ was significantly higher than that in PZM3 $+\mathrm{G}(\mathrm{P}<0.05$, Fig. 5), and the values in $\mathrm{PZM} 3+\mathrm{F}, \mathrm{PZM} 3$ and $\mathrm{PZM}+\mathrm{G}$ were $39 \%, 26 \%$ and $5 \%$, respectively.

\section{Experiment 2: Effects of glucose or fructose addition to a chemically defined medium without pyruvate and lactate (PZM) on preimplantation development}

From the results in Experiment 1, the proportion of hatching/ hatched blastocyst at $216 \mathrm{~h}$ was significantly higher in the groups supplemented with fructose when hexoses were added beginning at $72 \mathrm{~h}$ after electrostimulation, but not when they were added beginning at $48 \mathrm{~h}$ (Figs. 4 and 5). Therefore, hexoses were added beginning at $4 \mathrm{~h}$ or $72 \mathrm{~h}$ in Experiment 2.

When hexoses were added to $\mathrm{PZM}(\mathrm{PZM}+\mathrm{F}$ and $\mathrm{PZM}+\mathrm{G})$ beginning at $4 \mathrm{~h}$ after electrostimulation, there were no significant differences in the proportion of 2-cell stage diploids among the experimental groups, but the proportion of 4-cell stage diploids at $48 \mathrm{~h}$ was significantly lower in the PZM group (negative control) than in the other experimental groups ( $\mathrm{P}<0.05$, Fig. 6 ). The proportion of morula stage embryos at $96 \mathrm{~h}$ was significantly lower in PZM+F and PZM than in PZM3 (positive control), $\mathrm{PZM} 3+\mathrm{G}$ and $\mathrm{PZM}+\mathrm{G}$. Finally, almost none of the diploids in PZM+F and PZM developed to the morula stage ( $3 \%$ and $0 \%$, respectively); that is, diploids ceased development at the cleavage stages, and then the cell membrane of most diploids seemed to be unclear, a feature of degeneration, by $144 \mathrm{~h}$. In the groups supplemented with glucose $(\mathrm{PZM} 3+\mathrm{G}$ and $\mathrm{PZM}+\mathrm{G}$ ), the proportions of the diploids that developed normally at each observation point did not differ from those in PZM3 until $144 \mathrm{~h}$. On the other hand, the proportion of diploids at the blastocyst stage was significantly lower in PZM $3+\mathrm{G}$ and $\mathrm{PZM}+\mathrm{G}$ than in PZM3 at $120 \mathrm{~h}$ and $144 \mathrm{~h}(\mathrm{P}<0.05)$. A difference was also observed in the proportion of the normally developed diploids, which were expanded and hatching/hatched blastocysts, between PZM3 and PZM3 $+\mathrm{G}$ after $168 \mathrm{~h}$ and $192 \mathrm{~h}(\mathrm{P}<0.05)$ but not between PZM3

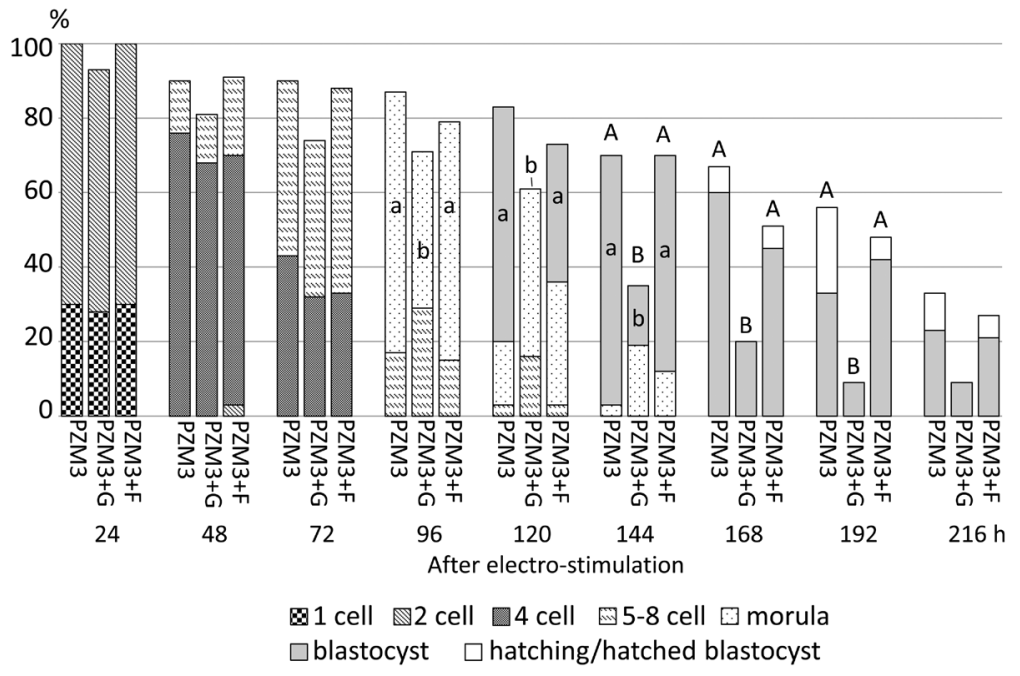

Fig. 3. Development of parthenogenetically activated pig diploids cultured in $P Z M 3$ or PZM 3 supplemented with glucose (PZM $3+\mathrm{G})$ or fructose $(\mathrm{PZM} 3+\mathrm{F})$ from $4 \mathrm{~h}$ to $216 \mathrm{~h}$ after electrostimulation. Trials were repeated at least three times in each experimental group, and the total numbers of diploids for analysis were 30, 31 and 33 for those cultured in PZM3, PZM3 $+\mathrm{G}$ and PZM3 $+F$, respectively. The different small letters (a,b) indicate significant differences in the proportions of diploids that developed to the most advanced stage at each observation point among the experimental groups $(\mathrm{P}<0.05)$. The different capital letters $(\mathrm{A}, \mathrm{B})$ indicate significant differences in proportions of diploids that normally developed at each observation period among the experimental groups $(\mathrm{P}<0.05)$. 


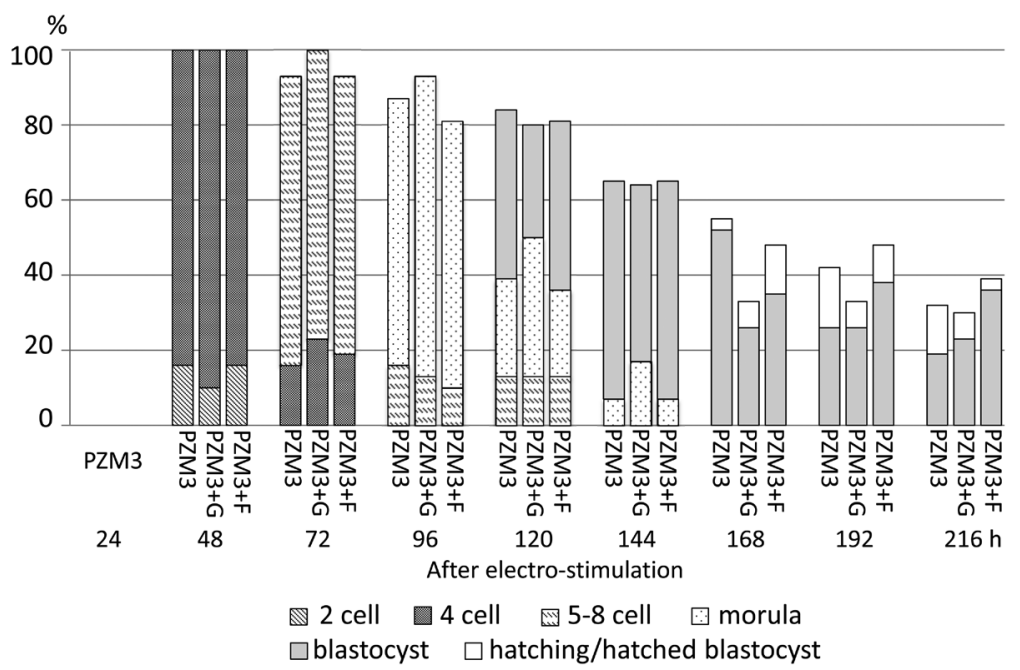

Fig. 4. Development of parthenogenetically activated pig diploids cultured in PZM3 or PZM3 supplemented with glucose (PZM3 $+\mathrm{G})$ or fructose $(\mathrm{PZM} 3+\mathrm{F})$ from $48 \mathrm{~h}$ to $216 \mathrm{~h}$ after electrostimulation. All diploids were cultured in PZM3 until $48 \mathrm{~h}$. Trials were repeated at least three times in each experimental group, and the total numbers of diploids that were cultured in PZM3, PZM3+G and PZM3+F were 31, 30 and 31, respectively. There were no significant differences in the proportions of diploids that developed to the most advanced stage and normally developed diploids at each observation point among the experimental groups.

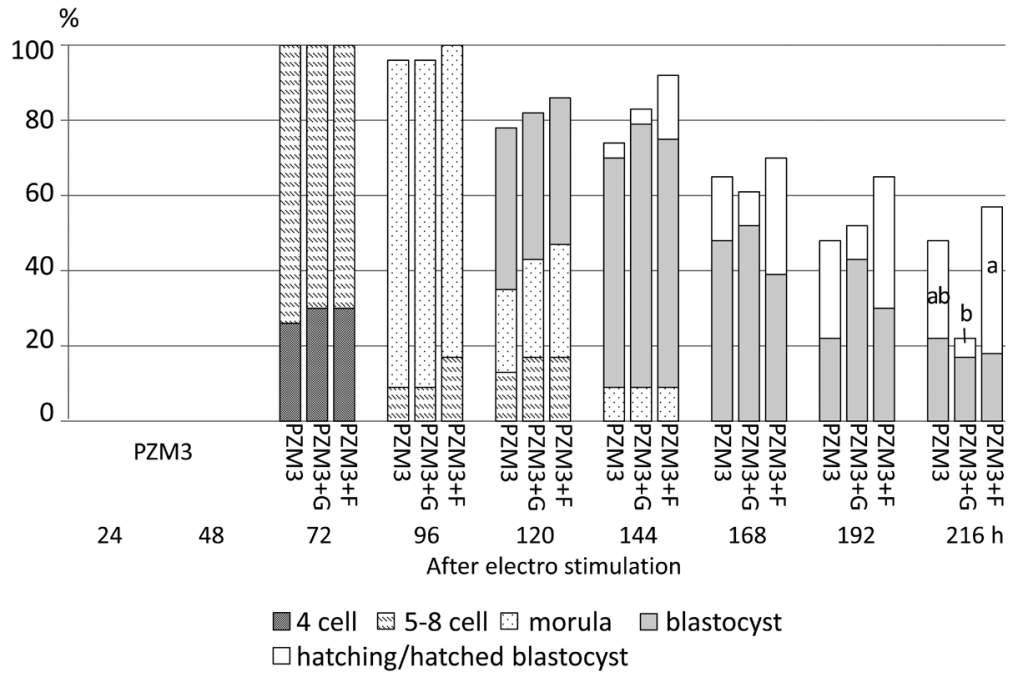

Fig. 5. Development of parthenogenetically activated pig diploids cultured in PZM3 or PZM3 supplemented with glucose (PZM3+G) or fructose $(\mathrm{PZM} 3+\mathrm{F})$ from $72 \mathrm{~h}$ to $216 \mathrm{~h}$ after electrostimulation. All diploids were cultured in PZM3 until $72 \mathrm{~h}$. Trials were repeated at least three times in each experimental group, and the total number of diploids was 23 in each experimental group. The different small letters (a, b) indicate significant differences in the proportions of diploids that developed to the most advanced stage at each observation point among the experimental groups $(\mathrm{P}<0.05)$. There were no significant differences in the proportions of diploids that developed normally at each observation period among the experimental groups.

and $\mathrm{PZM}+\mathrm{G}(\mathrm{P}>0.05)$.

When fructose and glucose were added to PZM3 after $72 \mathrm{~h}$, only the 4-cell diploids cultured in PZM3 were collected and subsequently cultured until $216 \mathrm{~h}$ after electrostimulation. From $72 \mathrm{~h}$ to $168 \mathrm{~h}$, the proportion of diploids that normally developed in each culture period showed no difference among any of the groups (Fig. 7), but blastocysts derived from PZM+F at $144 \mathrm{~h}$ tended to have large cell numbers $(\mathrm{P}>0.05)$ (Fig. 8). There was no significant difference in the apoptotic index in blastocysts obtained at $144 \mathrm{~h}$ among PZM3, $\mathrm{PZM}+\mathrm{G}, \mathrm{PZM}+\mathrm{F}$ and PZM (Fig. 8). A typical result of TUNEL analysis is shown in Fig. 9. Furthermore, the proportion of surviving blastocysts was significantly higher in PZM+F than in PZM3 at 192 $\mathrm{h}$ and was significantly higher in $\mathrm{PZM}+\mathrm{F}$ and in $\mathrm{PZM}+\mathrm{G}$ than in PZM3 and in PZM at $216 \mathrm{~h}$ after electrostimulation (Fig. 7). 


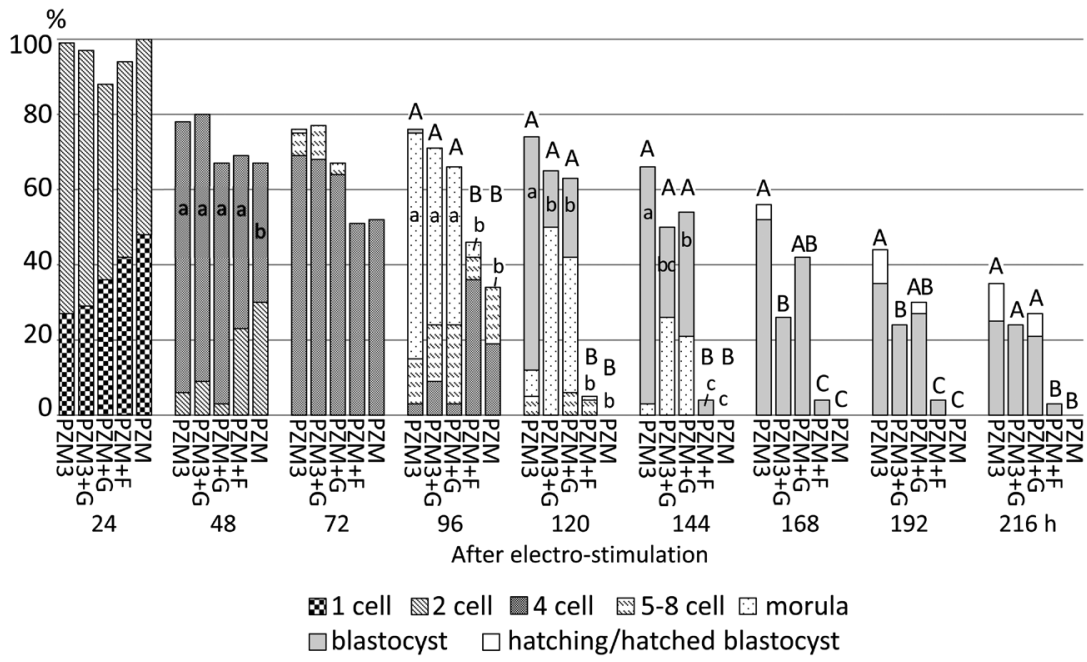

Fig. 6. Development of parthenogenetically activated pig diploids cultured in PZM3, PZM3 supplemented with glucose (PZM3+G), PZM supplemented with glucose $(\mathrm{PZM}+\mathrm{G})$ or fructose $(\mathrm{PZM}+\mathrm{F})$ or $\mathrm{PZM}$ from $4 \mathrm{~h}$ to $216 \mathrm{~h}$ after electrostimulation. Trials were repeated at least three times in each experimental group, and the total numbers of diploids for the analysis were 86, 34, 33, 69 and 27 for those cultured in PZM3, PZM3 $+\mathrm{G}, \mathrm{PZM}+\mathrm{G}$ $\mathrm{PZM}+\mathrm{F}$ and PZM, respectively. The different small letters $(\mathrm{a}-\mathrm{c})$ indicate significant differences in the proportions of diploids that developed to the most advanced stage at each observation point among the experimental groups $(\mathrm{P}<0.05)$. The different capital letters $(\mathrm{A}-\mathrm{C})$ indicate significant differences in proportions of diploids that developed to the blastocyst and hatching/hatched blastocyst stages among the experimental groups ( $\mathrm{P}$ $<0.05)$.

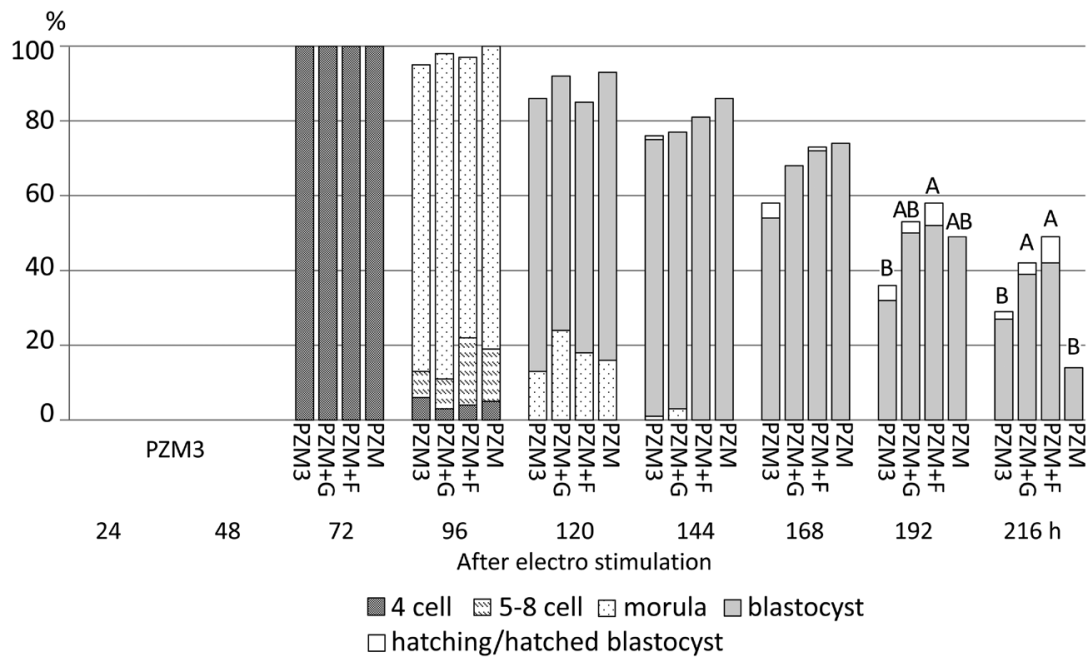

Fig. 7. Development of parthenogenetically activated pig diploids cultured in PZM3, PZM supplemented with glucose (PZM+G) or fructose (PZM+F) or PZM from $72 \mathrm{~h}$ to $216 \mathrm{~h}$ after electrostimulation. All diploids were cultured in PZM3 until $72 \mathrm{~h}$. Trials were repeated at least three times in each experimental group, and total numbers of diploids for the analysis were 85, 38, 67 and 43 for those cultured in PZM3, PZM+G, PZM+F and PZM, respectively. There were no significant differences in the proportions of diploids that developed to the most advanced stage at each observation point among the experimental groups. The different capital letters (A, B) indicate significant differences in proportions of diploids that developed to the blastocyst and hatching/hatched blastocyst stages among the experimental groups $(\mathrm{P}<0.05)$.

Experiment 3: mRNA expressions of the glycolytic enzymes hexokinase II (HKII), glucokinase (Gck) and ketohexokinase (KHK) in embryos during preimplantation development

The results of RT-PCR are shown in Fig. 10. HKII and Gck mRNAs were detected in diploids at every developmental stage. On the other hand, $K H K$ mRNA was detected in metaphase II oocytes and normally developed diploids later than $72 \mathrm{~h}$ after electrostimulation.

\section{Discussion}

In the present study, parthenogenetically activated diploids were cultured in a chemically defined medium with different carbohydrates, 


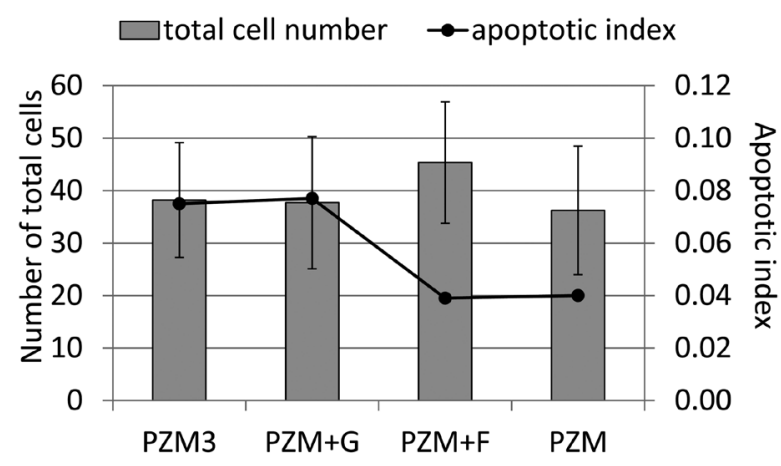

Fig. 8. The total numbers of cells and apoptotic indexes in blastocysts. Parthenogenetic diploids were cultured in PZM3 until $72 \mathrm{~h}$ and then cultured until $144 \mathrm{~h}$ in PZM3, PZM+G, PZM+F or PZM. The numbers of diploids cultured in PZM3, $\mathrm{PZM}+\mathrm{G}, \mathrm{PZM}+\mathrm{F}$ and PZM were 43, 19, 17 and 21, respectively. Trials were carried out at least three times for each experimental group. There were no significant differences in the number of cells or the ratio of apoptotic cells among blastocysts that were cultured in PZM3, $\mathrm{PZM}+\mathrm{G}, \mathrm{PZM}+\mathrm{F}$ and $\mathrm{PZM}$. Apoptotic index $=$ number of apoptotic cells / number of cells in a blastocyst.

and the characteristics of pig preimplantation development were examined to investigate the utility of a carbohydrate(s), such as glucose, fructose, pyruvate and lactate, and a combination of glucose or fructose with pyruvate and lactate. For assistance in understanding the hexoses used by pig preimplantation embryos, the expression of $H K I I, G C K$ and $K H K$ mRNA was also examined in diploids at different developmental stages.

In Experiment 1, we examined whether the addition of glucose or fructose to PZM3 that included pyruvate and lactate had effects on the development of pig parthenogenetic diploids to the blastocyst stage. The proportions of morulae at $96 \mathrm{~h}$, blastocysts at $120 \mathrm{~h}$ and $144 \mathrm{~h}$ and normally developed diploids later than $144 \mathrm{~h}$, except for at 216 $\mathrm{h}$, were significantly lower in diploids cultured in PZM3 $+\mathrm{G}$ than in those cultured in PZM3 and in PZM3+F, when hexoses were present throughout the culture period beginning at $4 \mathrm{~h}$ after electrostimulation $(\mathrm{P}<0.05)$. The normally developed diploids meant only expanding and hatching/hatched blastocysts later than $168 \mathrm{~h}$. When glucose was present from $48 \mathrm{~h}$ or $72 \mathrm{~h}$ after electrostimulation, however, the proportion of blastocyst formation was not affected. On the other hand, the presence of fructose from $4 \mathrm{~h}$ after electrostimulation did not result in a decrease in blastocyst formation. Furthermore, when hexoses were added to PZM3 from $72 \mathrm{~h}$ after electrostimulation, the proportion of total blastocysts and hatching/hatched blastocysts was rather high in PZM3 $+F$ when compared with that in PZM3 at $144 \mathrm{~h}(\mathrm{P}>0.05)$. These results indicate that the presence of glucose during early cleavage stages is suppressive for pig preimplantation development, whereas fructose was not, and that fructose rather stimulates post-blastoration development in pig embryos.

In Experiment 2, we examined whether the addition of glucose or fructose to PZM, which did not include pyruvate and lactate $(\mathrm{PZM}+\mathrm{G}$ and $\mathrm{PZM}+\mathrm{F}$, respectively), affected preimplantation development of pig parthenogenetic diploids to the blastocyst stage. Addition of glucose to PZM beginning at $4 \mathrm{~h}$ resulted in a decrease in the proportion
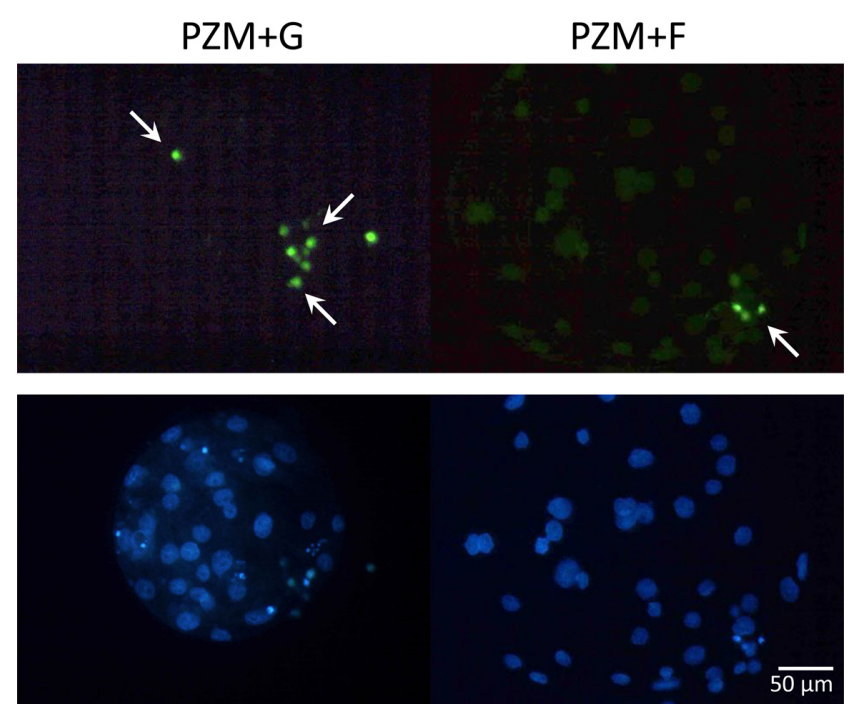

Fig. 9. Typical images of TUNEL analysis in blastocysts that were cultured in $\mathrm{PZM}+\mathrm{G}$ (left panels) or $\mathrm{PZM}+\mathrm{F}$ (right panels) up to 144 h. Fixed blastocysts were stained for apoptosis using the DeadEnd Fluorometric TUNEL assay (green, upper panels). Apoptotic cells are indicated by arrows. Nuclei were counterstained with Hoechst 33342 (blue, lower panels).

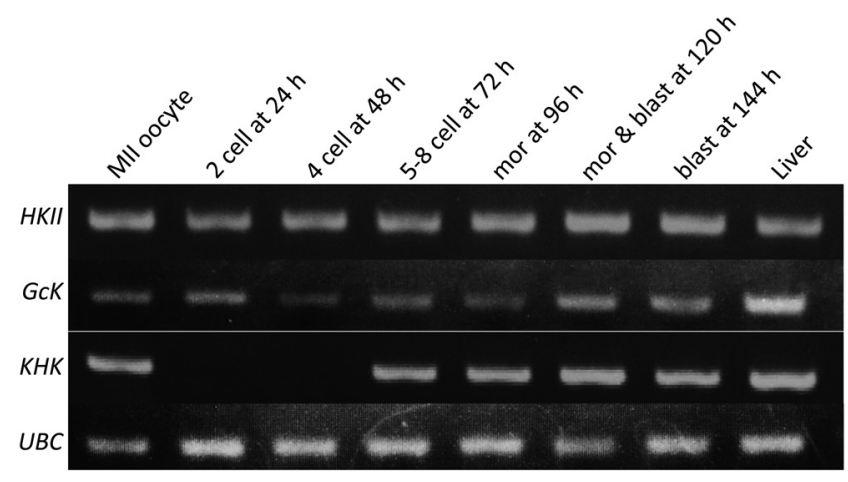

Fig. 10. Detection of mRNA expression by reverse-transcribed PCR in pig parthenogenetic diploids cultured in PZM3. HKII, Hexokinase II; GcK, glucokinase; KHK, ketohexokinase; UBC, ubiquitin. mor, morula; blast, blastocyst.

of blastocysts 120 and $144 \mathrm{~h}$ after electrostimulation similar to that when it was added to PZM3. Thus, the best result of preimplantation development was obtained when pig parthenogenetic diploids were cultured in a medium with pyruvate and lactate and hexoses were not supplemented from the beginning of the culture period. Glucose alone could support preimplantation development from activation to the blastocyst stage. However, addition of glucose to PZM3, which included pyruvate and lactate $(P Z M 3+G)$, suppressed the proportions of blastocyst formation at $144 \mathrm{~h}$ and normally developed embryos at 168 and $192 \mathrm{~h}$. When glucose was added beginning at 4 $\mathrm{h}$, the proportion of blastocyst formation at $120 \mathrm{~h}$ was significantly lower in PZM3 $+\mathrm{G}$ and $\mathrm{PZM}+\mathrm{G}$ than in PZM3. This developmental 
arrest at the morula stage was reflected in the lower proportions of blastocyst formation in the later periods. However, at $216 \mathrm{~h}$, there was no significant difference in blastocyst formation among PZM3, $\mathrm{PZM} 3+\mathrm{G}$ and $\mathrm{PZM}+\mathrm{G}$. It is unclear why pig embryonic development was restricted by the addition of glucose to PZM3, although addition of glucose alone $(\mathrm{PZM}+\mathrm{G})$ could support pig preimplantation development to the blastocyst stage.

When hexoses were added to PZM3 beginning at $48 \mathrm{~h}$ after electro stimulation in Experiment 1, diploids that reached the early 4-cell stage in PZM3 showed no significant differences in preimplantation development in any of the observation periods, although the proportions of normally developed embryos were generally lower in $\mathrm{PZM} 3+\mathrm{G}$ than in PZM3 and PZM3 $+\mathrm{F}$ in all observation periods later than $168 \mathrm{~h}(\mathrm{P}>0.05)$. When hexoses were added beginning at $72 \mathrm{~h}$, the proportions of normally developed diploids in PZM3+G were approximately similar to those in PZM3 until $192 \mathrm{~h}$ after electrostimulation. On the other hand, when hexoses were supplemented to PZM beginning at $72 \mathrm{~h}$ after electrostimulation in Experiment 2, the proportions of normally developed diploids, which were expanded and hatching/hatched blastocysts, was lowest in PZM3 at $168 \mathrm{~h}$ $(\mathrm{P}>0.05)$ and significantly lower in $\mathrm{PZM} 3$ than in $\mathrm{PZM}+\mathrm{G}$ and $\mathrm{PZM}+\mathrm{F}$ at $216 \mathrm{~h}$ after electrostimulation $(\mathrm{P}<0.05)$. It was previously reported that pig blastocysts were produced most efficiently when in-vitro fertilized eggs were cultured in NCSU-37, the glucose in which had been replaced with pyruvate and lactate, until $53 \mathrm{~h}$ after insemination and then cultured in NCSU-37 including glucose [9]. The present results using PZM and PZM3 were fundamentally similar to the results obtained using NCSU-37. The present results also confirmed previous results indicating that pyruvate and lactate are more effective energy sources than glucose or fructose for the development of pig embryos to the blastocyst stage [11, 15]. It was also reported that the addition of $2.5 \mathrm{mM}$ to $10 \mathrm{mM}$ glucose on day 5 to PZM5, the L-glutamine concentration of which is twice that of PZM3 (2.0 mM and 1.0 mM, respectively), increased the survival rate of pig blastocysts on day 7 [10].

The results of Experiment 2 revealed two distinct features of pig preimplantation development. First, the proportions of morulae at 96 $\mathrm{h}$ and blastocysts later than $120 \mathrm{~h}$ were significantly and extremely lower in diploids that were cultured in PZM+F beginning at $4 \mathrm{~h}$ after electrostimulation as are those in PZM which included no carbohydrate as a major energy source than those in PZM3, PZM3 $+\mathrm{G}$ and $\mathrm{PZM}+\mathrm{G}$. It was reported that culture of in-vitro fertilized eggs in NCSU-23 supplemented with fructose alone or without an energy substrate resulted in very low cleavage proportions and no blastocyst formation [15]. These results indicate that pig embryos cannot efficiently metabolize fructose until the late 4-cell stage and seldom develop beyond the 4-cell stage. Second, it should be realized that pig late 4-cell embryos after culture for $72 \mathrm{~h}$ in PZM3 can develop to the blastocyst stage, show expansion and enter the hatching process in a medium without any carbohydrate but with essential and nonessential amino acid mixtures at the same level as those cultured in a medium that includes carbohydrates and the amino acid mixtures. Although the proportion of surviving blastocysts in $\mathrm{PZM}+\mathrm{G}$ and $\mathrm{PZM}+\mathrm{F}$ slowly decreased from $144 \mathrm{~h}$ to $216 \mathrm{~h}$, it was significantly higher than those in PZM3 and PZM at $216 \mathrm{~h}$ after electrostimulation. One reason for the low proportion of surviving blastocysts in PZM3 and PZM may be the rapid increase in energy requirement of hatching and hatched blastocysts. Blastocysts on day 6 had approximately three times higher ATP when in vitro fertilized embryos were cultured in PZM5 with the addition of glucose on day 5 than when they were cultured in PZM5 without the addition of glucose [10]. These facts suggest that depletion of ATP may cause low viability of pig blastocysts after they start strong expansion beginning at $168 \mathrm{~h}$ after electrostimulation.

We also examined the mRNA expression of hexokinase II (HKII), glucokinase (GCK) and ketohexokinase (KHK), whose transcripts were involved in glucose and/or fructose metabolism. HKII and GcK catalyze glucose phosphorylation, which is the first step of glucose metabolism via glycolysis. KHK catalyzes fructose phosphorylation, which is the first step of fructose metabolism via glycolysis. HKII and $G C K$ mRNAs were expressed throughout all stages of preimplantation development, while $K H K$ mRNA expression was not observed at either the 2-cell or 4-cell stage. These results suggest that diploids can use glucose as their energy substrate throughout preimplantation development; however, they cannot use fructose in the early cleavage stage. HKII can catalyze both glucose and fructose, but in this study, fructose may not be metabolized efficiently by HKII, because diploids cultured throughout the experimental period in $\mathrm{PZM}+\mathrm{F}$ hardly developed beyond the 4-cell stage in Experiment 2. Therefore, it was considered that fructose was mainly metabolized by KHK, which can catalyze ketose under the conditions used in this study. It seems that pig embryos can use fructose from the late 4-cell or morula stage, and so both glucose and fructose become usable energy substrates for pig embryos. GCK mRNA expression in pig diploids also suggests that pig embryos can use glucose throughout preimplantation development, but it is still unclear why the addition of glucose to PZM3 during the early cleavage stage does not improve pig embryo development but rather works to suppress it.

\section{Acknowledgments}

This study was supported by JSPS Grant-in-Aid for Scientific Research (B), Grant Number 25292160.

\section{References}

1. Ludwig TE, Lane M, Bavister BD. Differential effect of hexoses on hamster embryo development in culture. Biol Reprod 2001; 64: 1366-1374. [Medline] [CrossRef]

2. Chatot CL, Ziomek CA, Bavister BD, Lewis JL, Torres I. An improved culture medium supports development of random-bred 1-cell mouse embryos in vitro. J Reprod Fertil 1989; 86: 679-688. [Medline] [CrossRef]

3. Kim JH, Funahashi H, Niwa K, Okuda K. Glucose requirement at different developmental stages of in vitro fertilized bovine embryos cultured in semi-defined medium. Theriogenology 1993; 39: 875-886. [Medline] [CrossRef]

4. Wright RW Jr. Successful culture in vitro of swine embryos to the blastocyst stage. $J$ Anim Sci 1977; 44: 854-858. [Medline]

5. Beckmann LS, Day BN. Effects of media $\mathrm{NaCl}$ concentration and osmolarity on the culture of early-stage porcine embryos and the viability of embryos cultured in a selected superior medium. Theriogenology 1993; 39: 611-622. [Medline] [CrossRef]

6. Miyano T, Hiro-Oka RE, Kano K, Miyake M, Kusunoki H, Kato S. Effects of hyaluronic acid on the development of 1- and 2-cell porcine embryos to the blastocyst stage in vitro. Theriogenology 1994; 41: 1299-1305. [Medline] [CrossRef]

7. Petters RM, Wells KD. Culture of pig embryos. J Reprod Fertil Suppl 1993; 48: 61-73. [Medline]

8. Flood MR, Wiebold JL. Glucose metabolism by preimplantation pig embryos. $J$ Reprod Fertil 1988; 84: 7-12. [Medline] [CrossRef] 
9. Karja NW, Medvedev S, Onishi A, Fuchimoto D, Iwamoto M, Otoi T, Nagai T. Effect of replacement of pyruvate/lactate in culture medium with glucose on preimplantation development of porcine embryos in vitro. $J$ Reprod Dev 2004; 50: 587-592. [Medline] [CrossRef]

10. Mito T, Yoshioka K, Yamashita S, Suzuki C, Noguchi M, Hoshi H. Glucose and glycine synergistically enhance the in vitro development of porcine blastocysts in a chemically defined medium. Reprod Fertil Dev 2012; 24: 443-450. [Medline] [CrossRef]

11. Yoshioka K, Suzuki C, Tanaka A, Anas IM, Iwamura S. Birth of piglets derived from porcine zygotes cultured in a chemically defined medium. Biol Reprod 2002; 66: 112-119. [Medline] [CrossRef]

12. Bhuiyan MM, Kang SK, Lee BC. Supplementation of fructose in chemically defined protein-free medium enhances the in vitro development of bovine transgenic cloned embryos. Zygote 2007; 15: 189-198. [Medline] [CrossRef]

13. Kwun J, Chang K, Lim J, Lee E, Lee B, Kang S, Hwang W. Effects of exogenous hexoses on bovine in vitro fertilized and cloned embryo development: Improved blastocyst formation after glucose replacement with fructose in a serum-free culture medium. Mol Reprod Dev 2003; 65: 167-174. [Medline] [CrossRef]

14. Wongsrikeao P, Otoi T, Taniguchi M, Karja NW, Agung B, Nii M, Nagai T. Effects of hexoses on in vitro oocyte maturation and embryo development in pigs. Theriogenology 2006; 65: 332-343. [Medline] [CrossRef]

15. Park Y, Hong J, Yong H, Lim J, Lee E. Effect of exogenous carbohydrates in a serum-free culture medium on the development of in vitro matured and fertilized porcine embryos. Zygote 2005; 13: 269-275. [Medline] [CrossRef]

16. Jarrell VL, Day BN, Prather RS. The transition from maternal to zygotic control of development occurs during the 4-cell stage in the domestic pig, Sus scrofa: quantitative and qualitative aspects of protein synthesis. Biol Reprod 1991; 44: 62-68. [Medline] [CrossRef]

17. Nguyen VT, Kure-bayashi S, Harayama H, Nagai T, Miyake M. Stage-specific effects of the osmolarity of a culture medium on the development of parthenogenetic diploids in the pig. Theriogenology 2003; 59: 719-734. [Medline] [CrossRef]

18. Kuijk EW, du Puy L, van Tol HT, Haagsman HP, Colenbrander B, Roelen BA. Validation of reference genes for quantitative RT-PCR studies in porcine oocytes and preimplantation embryos. BMC Dev Biol 2007; 7: 58. [Medline] [CrossRef]

19. Kure-Bayashi S, Miyake M, Katayama M, Miyano T, Kato S. Development of porcine blastocysts from in vitro- matured and activated haploid and diploid oocytes. Theriogenol ogy 1996; 46: 1027-1036. [Medline] [CrossRef] 